\title{
Making a good impression-on the phone
}

\author{
Norman Mortell, BA (Hons), RAnTech, MIAT \\ Honing your phone skills can help you land the job you want
}

We make an instant impression on people when we first interact with them-even if that interaction is over the phone. An excellent telephone manner can make a person seem more professional, friendly, and outgoing; poor phone skills can cost you a potential job. Some basic telephone skills can ensure that you make the right impression on prospective employers.

\section{When to phone}

Phoning is personal, immediate, and less formal than writing. It is the best way to keep in touch with your contacts, your recruitment agencies and consultants, and your references, as well as to request background information, sales literature, and annual reports in preparation for interviews. The informality of a phone call makes it the ideal way to request feedback on your performance from the recruiter if you did not get the job or-if you did-to thank all those who helped. The best time to phone is at lunchtime or just outside working hours. The person you are trying to contact will be less busy at these times and the secretary is less likely to be there to intercept calls.

\section{Do you like what you hear?}

Hearing ourselves speak on an audiotape or on a video recording can be quite a shock. You can improve your voice and technique by recording yourself and paying attention to your tone, inflection, articulation, and mood. It is a good idea to practice until you sound natural, clear, enthusiastic, calm, confident, cheerful, and in control.

Norman Mortell is Director at the Hull-UK-based Agenda Resource Management, a company that specializes in recruitment. He is also Editor of $\mathrm{Lab}$ Animal Europe.Email: jobs@agenda-rm.co.uk.URL: http://www.agenda-rm.co.uk.

\section{Be prepared}

Preparation and planning are essential for ensuring that that important telephone call is a success. To do so, focus on what you want from the call, plan what you are going to say, prepare your paperwork, and relax.

\section{More telephone tips}

The following are some additional suggestions that may improve your telephone skills:

- Stand up while talking; this assists with breathing

- Talk with a 'smile' in your voice

- Prepare a confident opening to your conversation

- Say what you need to say, but don't talk too much

- Be reasonably persistent if barriers are put in your way

- Take the hint if you are getting nowhere

- Always sound confident but polite

- Check understanding to ensure the person knows what you mean

- Be alert to the other person's responses

- Actively listen to what is said

- Avoid a distracting environment (for example, try not to have the children running around)

- Try to remember names and voices for the next time you ring

- Have a short script in case you encounter voicemail or answering machines

- Don't 'ummm' and 'ahhh'

- Be clear and concise, especially if you leave a contact number; a garbled message may mean no response

- Keep secretaries and receptionists on your side

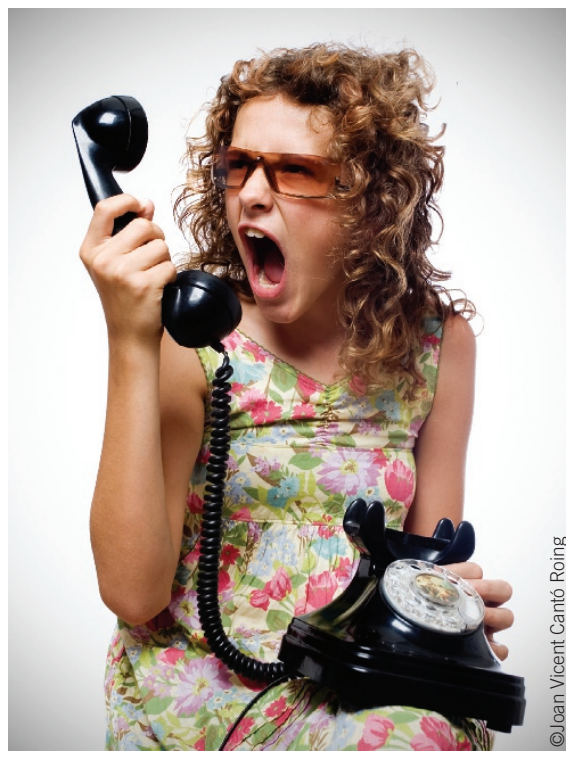

\section{Security note}

When you make the call, be prepared to identify who you are and the purpose for your call; research organisations are often security-conscious and may screen sales calls or even animal rights groups trying to obtain information about the organization. Be sensitive to this fact. Have the names and numbers of the people you would like to speak with and clearly explain the purpose of your call. Don't be surprised if a company is hesitant to give out the personal details of their employees.

\section{Conclusion}

We are not all confident extroverts on the phone, but these simple tips should help you make a positive impression. Remember the times when you have commented that a person sounds friendly or professional on the phone? Your goal should be to have people say the same things about you. 